\title{
The semi-dwarfing gene Rht-dp from dwarf polish wheat (Triticum polonicum L.) is the "Green Revolution" gene Rht-B1b
}

Songyue Chai ${ }^{1}$, Qin Yao ${ }^{1}$, Xu Zhang ${ }^{1}$, Xue Xiao ${ }^{1}$, Xing Fan ${ }^{1}$, Jian Zeng ${ }^{2}$, Lina Sha ${ }^{1}$, Houyang Kang ${ }^{1}$, Haiqin Zhang ${ }^{1}$, Jun $\mathrm{Li}^{3}$, Yonghong Zhou ${ }^{1 *}$ and Yi Wang ${ }^{1 *}$

\begin{abstract}
Background: The wheat dwarfing gene increases lodging resistance, the grain number per spike and harvest index. Dwarf Polish wheat (Triticum polonicum L., $2 n=4 x=28, A A B B, D P W$ ), initially collected from Tulufan, Xinjiang, China, carries a semi-dwarfing gene Rht-dp on chromosome 4BS. However, Rht-dp and its dwarfing mechanism are unknown.

Results: Homologous cloning and mapping revealed that Rht-dp is the 'Green Revolution' gene Rht-B1b. A haplotype analysis in 59 tetraploid wheat accessions showed that Rht-B1b was only present in T. polonicum. Transcriptomic analysis of two pairs of near-isogenic lines (NILs) of DPW $\times$ Tall Polish wheat (Triticum polonicum L., $2 n=4 x=28, A A B B, T P W$ ) revealed 41 differentially expressed genes (DEGs) as potential dwarfism-related genes. Among them, 28 functionally annotated DEGs were classed into five sub-groups: hormone-related signalling transduction genes, transcription factor genes, cell wall structure-related genes, reactive oxygen-related genes, and nitrogen regulation-related genes.
\end{abstract}

Conclusions: These results indicated that Rht-dp is Rht-B1b, which regulates pathways related to hormones, reactive oxygen species, and nitrogen assimilation to modify the cell wall structure, and then limits cell wall loosening and inhibits cell elongation, thereby causing dwarfism in DPW.

Keywords: Dwarf polish wheat, Homologous cloning, Molecular mapping, Rht-B1b, RNA-seq

\section{Background}

Plant height is an important agronomic trait of crops. The discovery and utilization of semi-dwarfing genes in rice (Oryza sativa) and wheat (Triticum aestivum) triggered the "Green Revolution", as dwarfism not only improves lodging resistance [1], but also increases the grain number per spike and harvest index [2, 3]. Increasing numbers of dwarf varieties of crops are being bred for

\footnotetext{
* Correspondence: zhouyh@sicau.edu.cn; wangyi@sicau.edu.cn 'Triticeae Research Institute, Sichuan Agricultural University, Wenjiang, Chengdu 611130, Sichuan, China

Full list of author information is available at the end of the article
}

production [4], and the dwarfing mechanisms in many crops are clearly revealed [5-7].

In wheat, 27 dwarfing genes including 32 alleles are present on chromosomes $2 \mathrm{~A}, 2 \mathrm{~B}, 2 \mathrm{D}, 3 \mathrm{~B}, 4 \mathrm{~B}, 4 \mathrm{D}, 5 \mathrm{~A}$, $5 \mathrm{D}, 6 \mathrm{~A}, 7 \mathrm{~A}$, and 7B [8-16]. Twenty-two of those genes were discovered from hexaploid wheat, including $R h t 1$ (Rht-B1b), Rht2 (Rht-D1b), Rht8, and Rht12. Those genes are widely utilized to breed new cultivars while only $R h t 1$ and $R h t 2$ have been cloned $[6,17,18]$. As the parent of hexaploid wheat, tetraploid wheat owns many dwarfing genes, for example, Rht14, Rht15, Rht16, Rht18, Rht19, and Rht-R107 in Triticum durum [19, 20], Rht22 in T. turgidum [21], contains Rht-B1f in T. aethiopicum

(c) The Author(s). 2021 Open Access This article is licensed under a Creative Commons Attribution 4.0 International License, which permits use, sharing, adaptation, distribution and reproduction in any medium or format, as long as you give appropriate credit to the original author(s) and the source, provide a link to the Creative Commons licence, and indicate if changes were made. The images or other third party material in this article are included in the article's Creative Commons licence, unless indicated otherwise in a credit line to the material. If material is not included in the article's Creative Commons licence and your intended use is not permitted by statutory regulation or exceeds the permitted use, you will need to obtain permission directly from the copyright holder. To view a copy of this licence, visit http://creativecommons.org/licenses/by/4.0/ The Creative Commons Public Domain Dedication waiver (http://creativecommons.org/publicdomain/zero/1.0/) applies to the data made available in this article, unless otherwise stated in a credit line to the data. 
[15], and Rht-B1 ${ }^{I C 12196}$ and Rht-dp in T. polonicum [10, 14]. Due to T. polonicum has a high 1000-grain weight and accumulates high concentrations of zinc and iron in grains, it is recommended to be a valuable material for wheat genetic improvement [22]. However, the details of its dwarfing genes, $R h t-d p$ and $R h t-B 1^{I C 12196}$, are still unknown.

As a gibberellin (GA)-insensitive semi-dwarfing gene, $R h t-d p$ was identified from dwarf Polish wheat (DPW, $T$. polonicum) originally collected from Tulufan, Xinjiang province, China [10, 23]. Transcriptomic and proteomic analyses suggested that $R h t-d p$ is probably involved in the phenylpropanoid pathway. It was found to reduce the contents of lignin, cellulose, and S-adenosylmethionine, and increase the contents of flavonoids, which ultimately limits cell expansion and causes dwarfism [24]. Although those results indicated the potential mechanism of Rht-dp, the candidate gene of Rht-dp remained unknown. Genetic analysis of $F_{2}$ population derived from the cross of DPW and tall Polish wheat (TPW) indicated that $R h t-d p$ should be a recessive gene [10]. However, the separated threshold of plant height was significant larger than the plant height of DPW [10, 23], which implied that the effect of $R h t-d p$ on reducing plant height might be partially covered by one or more non-allelic loci. Further study mapped $R h t-d p$ onto chromosome 4BS between the SSR markers Xgpw3017 and Xwmc511, and suggested that Rht-dp may be an alternative allele at the Rht-B1 locus [10]. However, due to the limited numbers of $F_{2}$ plants and molecular markers used in the analysis, a genomic alignment against the genome of Triticum aestivum 'Chinese Spring' (IWGSC RefSeq v1.0) (International Wheat Genome Sequencing Consortium, 2018) indicated that the region between Xgpw3017 and Xwmc511 did not include the Rht-B1 locus. Additionally, Rht-B1b and its alleles are semidominant genes $[6,25,26]$. Thus, we can't confirm whether $R h t-d p$ is $R h t-B 1 b$ or its allele, or a new gene.

$R h t-B 1 b$ encodes a premature DELLA protein, which prevents GID1 from binding to its target [12]. The premature DELLA protein truncates the GA response, resulting in dwarfism. Rht-B1b originates from the native Japanese dwarf variety 'Norin 10' [27]. However, it was successfully transferred from 'Norin 10' to 'Cando' in the 1960s and widely used in durum wheat breeding [28]. Meanwhile, three alleles of Rht-B1b, Rht-B1f, Rht-R107, and Rht19, were also discovered from $T$. aethiopicum and $T$. durum, respectively $[15,19]$. Although DPW is originally collected from Tulufan, Xingjiang, China [23] and the progenitor of T. polonicum is neither 'Norin 10', T. aethiopicum nor T. durum [10, 29], we still hypothesized that the candidate gene of $R h t-d p$ may be $R h t-B 1 b$ or its one of alleles, because only $R h t-B 1 b$ and its alleles as dwarfing genes have been found on $4 \mathrm{BS}$ to date $[10,23,28,30]$.
To test this hypothesis and to understand the dwarfing mechanism of $R h t-d p$ in DPW, we firstly cloned $R h t-B 1$ to investigate sequence differences in $R h t-B 1$ between DPW and TPW. Secondly, we developed and applied a specific molecular marker of Rht-B1 and SSR markers on $4 \mathrm{BS}$ to genetically confirm the candidate region using three recombinant inbred lines (RILs). Thirdly, two pairs of near-isogenic line (NIL) obtained from the $\mathrm{F}_{7}$ population of DPW $\times$ TPW were conducted transcript analyses to reveal the molecular mechanism of Rht-dp; meanwhile, $F_{1}$ plants and a $F_{2}$ population derived from the cross of a pair of NIL were developed for further genetic analysis. Finally, we conducted a haplotype analysis of $R h t-d p$ to reveal the natural distribution among 59 tetraploid wheat accessions.

\section{Methods}

\section{Plant materials and growth conditions}

The DPW and TPW lines were originally collected from Tulufan, Xinjiang province, China, by Prof. Chi Yen and Junliang Yang (Sichuan Agricultural University, China) in the 1980s. The $F_{1}$ population of DPW $\times$ TPW and the $\mathrm{F}_{2}$ population (401 plants) derived from $\mathrm{DPW} \times \mathrm{TPW}$ were individually developed for trait investigation. Two RIL populations ( $\mathrm{F}_{7}$ including 330 lines and $\mathrm{F}_{8}$ including 300 lines) derived from $\mathrm{DPW} \times \mathrm{TPW}$, and a RIL population $\left(\mathrm{F}_{6}\right.$ including 194 lines) derived from DPW $\times$ Jianyangailanmai (AABB, $2 \mathrm{n}=4 \mathrm{x}=28, T$. turgidum L., Ailanmai), were developed for gene mapping. Two pairs of NILs (D_60/T_58, and D_33/T_35, D and T represent dwarf and tall phenotype, respectively) derived from two heterozygous $\mathrm{F}_{7}$ lines were selected for transcript analyses. Meanwhile, $F_{1}$ plants and a $F_{2}$ population (244 plants) derived from the cross of D_60 and T_58 were developed for trait investigation. The haplotype analysis was conducted using 59 tetraploid wheat accessions (Table S1).

DPW, TPW and their $F_{1}$ plants and $F_{2}$ population were grown at the Wenjiang experimental field of Sichuan Agricultural University, Chengdu, China, in the 2011-2012 (from October 2011 to June 2012) and 2012-2013 (from October 2012 to June 2013) wheat growing seasons. The $F_{7}$ and $F_{8}$ RIL populations of $\mathrm{DPW} \times \mathrm{TPW}$ were grown at two experimental fields (Wenjiang and Chongzhou) of Sichuan Agricultural University (Chengdu, China) in the 2017-2018 (from October 2017 to June 2018) and 2018-2019 (from October 2018 to June 2019) wheat growing seasons, respectively. The $\mathrm{F}_{6}$ RIL population, the $\mathrm{F}_{1}$ plants of $\mathrm{D}_{-}$ $60 \times \mathrm{T} \_58$, two pairs of NILs, and 59 tetraploid wheat accessions were grown at the Wenjiang experimental field in the 2018-2019 (from October 2018 to June 2019) wheat growing season. The $F_{2}$ population of $D_{-}$ $60 \times \mathrm{T} \_58$ was grown at the Wenjiang experimental field 
in the 2019-2020 (from October 2019 to June 2020) wheat growing season. Each line was planted with 20 plants per row. The rows were $2 \mathrm{~m}$ long and the spacing between rows was $30 \mathrm{~cm}$.

\section{Phenotypic measurements and analysis}

Plant height, spike length, and stem length were measured at maturity. We selected three individual plants per line and calculated the average value. Data was analysed using SPSS software (version 18.0; SPSS, Chicago, IL, USA) Figures were drawn using SigmaPlot software (version 12.0; Systat, Point Richmond, CA, USA).

\section{Homologous cloning of Rht-B1}

According to the genomic sequence of $T$. aestivum $\mathrm{cv}$. 'Chinese Spring' (IWGSC RefSeq v1.0), a pair of Rht-B1specific primers (forward: 5'-CGATGCCGTC TACAAC TACT-3'; reverse: 5'-CAACTCCTAGATCGGGAA ACTT-3') was designed using Beacon designer software (version 7.0; Premier Biosoft International, Palo Alto, CA, USA). These primers were used to amplify the fulllength Rht-B1 sequence from DPW and TPW. Each PCR reaction mixture contained $2 \mu \mathrm{l}$ DNA, $2 \mu \mathrm{l}$ mixture of forward and reverse primers $(4 \mathrm{pmol} / \mu \mathrm{l}), 2 \mu \mathrm{l} \mathrm{dNTP}$ $(2.5 \mathrm{mM} / \mu \mathrm{l}), 1 \mu \mathrm{l}$ Ex-Taq polymerase $(5 \mathrm{U} / \mu \mathrm{l}), 2 \mu \mathrm{l}$ $\mathrm{MgCl}_{2}(2.5 \mathrm{mM} / \mu \mathrm{l}), 2.5 \mu \mathrm{l} 10 \times \mathrm{PCR}$ buffer, and $13.5 \mu \mathrm{l}$ $\mathrm{dd}_{2} \mathrm{O}$. The PCR amplification conditions were $95^{\circ} \mathrm{C}$ for $5 \mathrm{~min}, 40$ cycles $\left(95^{\circ} \mathrm{C}\right.$ for $30 \mathrm{~s}, 58^{\circ} \mathrm{C}$ for $30 \mathrm{~s}$, and $72{ }^{\circ} \mathrm{C}$ for $2 \mathrm{~min}$ ), and final extension at $72{ }^{\circ} \mathrm{C}$ for $10 \mathrm{~min}$. Each amplified fragment was cloned into the pMD19-T vector for sequencing. Differences in Rht-B1 sequences between DPW and TPW were detected in an alignment analysis using Vector NTI software (version 11.5.1; Invitrogen, Carlsbad, CA, USA).

\section{Exploitation of indel marker of Rht-B1 for mapping} According to the sequence differences in Rht-B1 between DPW and TPW, a pair of Rht-B1-specific primers (Rht-B1 Indel-F: 5'-GGCGGGAGATCGAAGTAC-3', Rht-B1 Indel-R: 5'-GACACCGTGCACTACAAC-3') was designed using Beacon designer software.

\section{Exploitation of SSR markers on 4BS for mapping}

According to the genomic sequence of 4BS of T. aestivum cv. 'Chinese Spring' (IWGSC RefSeq v1.0) (http://plants. ensembl.org/), microsatellites were predicted using the MIcroSAtellite identification tool (https://webblast.ipkgatersleben.de/misa/) [31, 32]. Beacon designer software was used to design SSR markers (Table S2).

\section{Genotyping and genetic mapping}

Genomic DNA was extracted from DPW, TPW, Ailanmai and the mapping populations $\mathrm{RIL}_{6}$ (DPW $\times$ Ailanmai), $\mathrm{RIL}_{7}$ and $\mathrm{RIL}_{8}(\mathrm{DPW} \times \mathrm{TPW})$ using a plant genomic DNA kit (TIANGEN BIOTECH, Beijing, China). Each PCR reaction mixture contained $1 \mu \mathrm{l}$ DNA, $2 \mu \mathrm{l}$ mixture of forward and reverse primers $(4 \mathrm{pmol} / \mu \mathrm{l}), 1.5 \mu \mathrm{lNTP}(2.5$ $\mathrm{mM} / \mu \mathrm{l}), 0.5 \mu \mathrm{l}$ Taq polymerase $(5 \mathrm{U} / \mu \mathrm{l}), 1.5 \mu \mathrm{l} \mathrm{MgCl}_{2}(2.5$ $\mathrm{mM} / \mu \mathrm{l}), 2 \mu \mathrm{l} 10 \times \mathrm{PCR}$ buffer, and $11.5 \mu \mathrm{l} \mathrm{ddH}_{2} \mathrm{O}$. The PCR amplification conditions were $95^{\circ} \mathrm{C}$ for $5 \mathrm{~min}, 35 \mathrm{cy}$ cles $\left(95^{\circ} \mathrm{C}\right.$ for $45 \mathrm{~s}, 58^{\circ} \mathrm{C}$ for $45 \mathrm{~s}$, and $72^{\circ} \mathrm{C}$ for $\left.45 \mathrm{~s}\right)$, and final extension at $72{ }^{\circ} \mathrm{C}$ for $7 \mathrm{~min}$. The PCR products were separated on $8 \%$ polyacrylamide gels. The polymorphic bands between the parents were used to genotype individual lines of the mapping populations.

The Rht-B1 Indel marker and 15 polymorphic SSR markers were first used for genetic mapping of Rht-dp in the $\mathrm{F}_{7}$ RIL population. Then, Rht-B1Indel and its four flanking SSR markers (Xgpw2994.1, Xgpw3128.1, Xgpw3427.1, and Xgpw4800.1) were further used to confirm the candidate region in the $\mathrm{F}_{8}$ RIL and $\mathrm{F}_{6}$ RIL populations. The $\mathrm{F}_{7}$ RIL population was hybridized on the wheat $55 \mathrm{~K}$ SNP array by CapitalBio Technology (Beijing, China) (unpublished data).

Linkage analysis was performed using the JoinMap software (version 4.0; Kyazma BV, Wageningen, Netherlands) with a logarithm of odds (LOD) threshold of 3.0. The Kosambi mapping function was used to convert the recombination frequencies into genetic distances (cM) [33].

\section{Haplotype analysis of Rht-B1 in 59 tetraploid wheat accessions}

Genomic DNA was extracted from each tetraploid wheat accession using a plant genomic DNA kit (TIANGEN BIOTECH, Beijing, China), and PCR amplification was performed as described in the section "Homologous cloning of Rht-B1". The amino acid sequence was deduced using ExPASy software (http://web.expasy.org/ translate/). All sequences were aligned using Vector NTI software (Invitrogen). A phylogenetic tree was constructed using the neighbour-joining algorithm in MEGA5 (https://www.megasoftware.net/).

\section{Expression analysis of Rht-B1b}

Tissues at the three growth stages (jointing, booting, and grain filling stages) were collected, including roots, basal stems, leaf sheaths, leaf blades, young leaves, lower leaf blades, first and second internodes, flag leafs, and spikes. The collected tissues were snap-frozen in liquid nitrogen and stored at $-80^{\circ} \mathrm{C}$ until RNA extraction. Total RNA was extracted using a Plant RNA Kit (Omega Bio-Tek, American). cDNA was synthesized using the M-MLV First Strand cDNA Synthesis kit (Invitrogen).

Quantitative real-time PCR (qPCR) was performed on the CFX-96 system as described by Wang et al. using a pair of $R h t$-B1b-specific primers (forward: 5'-GGCGGG AGATCGAAGTAC-3'; reverse: 5'-GACACCGTGC 
ACTACAAC-3') [34]. To normalize gene expression levels, the Actin gene was used as the reference gene [34]. Relative expression levels were calculated according to the $2^{\Delta \Delta \mathrm{Ct}}$ method using the CFX Manager (version 3.1; Bio-Rad, Hercules, CA, USA).

\section{Transcript analysis of two pairs of NILs Sample collection}

At the booting stage, the first internode was collected individually from two pairs of NILs, and then snap-frozen in liquid nitrogen and stored at $-80^{\circ} \mathrm{C}$ until RNA extraction.

\section{RNA extraction, library preparation and sequencing}

Total RNA was isolated as described above, and RNA degradation and contamination were monitored on $1 \%$ agarose gels. A NanoPhotometer ${ }^{\bullet}$ spectrophotometer (Implen GmbH, Munich, Germany) RNA purity was used to check RNA purity. The mRNA was purified from total RNA using poly-T oligo-attached magnetic beads and divided into short fragments using NEBNext First Strand Synthesis Reaction Buffer (5x) (New England Biolabs, Ipswich, MA, USA). The cDNA was synthesized using the fragments as templates and then purified and resolved with EB buffer for the end-repair step and addition of a single adenine (A) nucleotide. To select cDNA fragments $250 \sim 300 \mathrm{bp}$ in length, the library fragments were purified with the AMPure XP system (Beckman Coulter, Beverly, CA, USA), and suitable fragments were chosen for a PCR amplification. The PCR products were purified (AMPure XP system) and the library quality was assessed using the Agilent Bioanalyzer 2100 system. The prepared libraries were sequenced on the Illumina Hiseq platform.

\section{RNA-seq data analysis}

Raw data (raw reads) of in fastq format were first processed using in-house perl scripts. In this step, clean data (clean reads) were obtained by removing reads containing adapters, reads containing poly- $\mathrm{N}$, and low-quality reads from the raw data. All the downstream analyses were conducted using clean, high-quality data.

The Chinese Spring (IWGSC RefSeq v1.0) reference genome and gene model annotation files were downloaded from the genome website (https://urgi.versailles. inra.fr/download/iwgsc/IWGSC_RefSeq_Assemblies/v1.0). The $\mathrm{D}$ genome sequences were excluded from the reference before mapping the processed reads of the tetraploid lines (A and B genomes). An index of the Chinese Spring reference genome was built using Bowtie v2.2.3 and paired-end clean reads were aligned to the reference genome using TopHat v2.0.12. HTSeq v0.6.1 was used to count the number of reads mapped to each gene. The mean fragments per kilobase of transcript per million mapped reads (FPKM) value for each gene was calculated based on the length of the gene and the number of reads mapped to it [35].

\section{Differential expression analysis}

Read counts were adjusted by the edgeR program package through one scaling normalized factor. Analysis of differential gene expression between two pairs of NILs (D33/T35 and D60/T58) was performed using the DEGSeq $\mathrm{R}$ package. The $P$ values were adjusted using the Benjamini and Hochberg method. A corrected $P$-value of 0.005 and $\log 2$ (fold change) of 1 were set as the thresholds for significantly different gene expression.

\section{QPCR for validation}

Two differentially expressed genes Auxin-repressed protein (ARP) and L-ascorbate oxidase homolog (ASCO) from RNA-Seq were verified by qPCR, and their genespecific primers sequences were $A P R$ (forward: $5^{\prime}$ ATTAAGCAGTCGCCG TCGAT-3'; reverse: 5' -TCGC TGTAAAGCCAG TCGTA - 3') and ASCO (forward: 5'-AATGGCAATAGGTTCACAGTAGA-3'; reverse: 5' -CTTCACGAGGAACGAGT AGG-3'), respectively.

\section{Results}

\section{Phenotype of plants harbouring Rht-dp}

The average heights of DPW and TPW were $91.52 \pm$ $2.97 \mathrm{~cm}$ and $189.88 \pm 1.72 \mathrm{~cm}$, respectively. No significant difference in plant heights between $F_{1}$ plants $(179.12 \pm 3.65 \mathrm{~cm})$ and TPW was observed (Fig. S1). The plant heights of $F_{2}$ plants ranged from 65 to $185 \mathrm{~cm}$. According to the frequency distribution of plant height, $\mathrm{F}_{2}$ plants were separated into two groups of dwarf and tall phenotypes at $110 \mathrm{~cm}$ (Fig. 1a). The dwarf and tall phenotype groups included 107 and 294 plants, respectively, consistent with the expected Mendelian segregation ratio of $1: 3\left(X^{2}=0.606, p<0.05\right)$. These results validate that $R h t-d p$ should be a major recessive gene. However, the separated threshold of plant height with $110 \mathrm{~cm}$ was significantly larger than the plant height of DPW with $91.52 \pm 2.97 \mathrm{~cm}$, which implied that the effect of $R h t-d p$ on reducing plant height might be partially covered by one or more non-allelic loci.

To fine-map $R h t-d p$, two RIL populations including $330 \mathrm{~F}_{7}$ and $300 \mathrm{~F}_{8}$ plants were constructed. The plant heights of $F_{7}$ and $F_{8}$ plants ranged from 65 to $165 \mathrm{~cm}$ (Fig. 1b) and from 65 to $170 \mathrm{~cm}$ (Fig. 1c), respectively. For the $\mathrm{F}_{7}$ population, the average heights of dwarf and tall phenotypes were $84.07 \pm 1.97 \mathrm{~cm}$ and $133.75 \pm 2.01$ $\mathrm{cm}$, respectively. Compared with the tall phenotype, the lines harbouring $R h t-d p$ showed a reduction in plant height of up to $37.14 \%$. The reduced plant height was because of the shortened first internode (by 14.83\%), second internode (by 7.15\%), and basal internode (by 


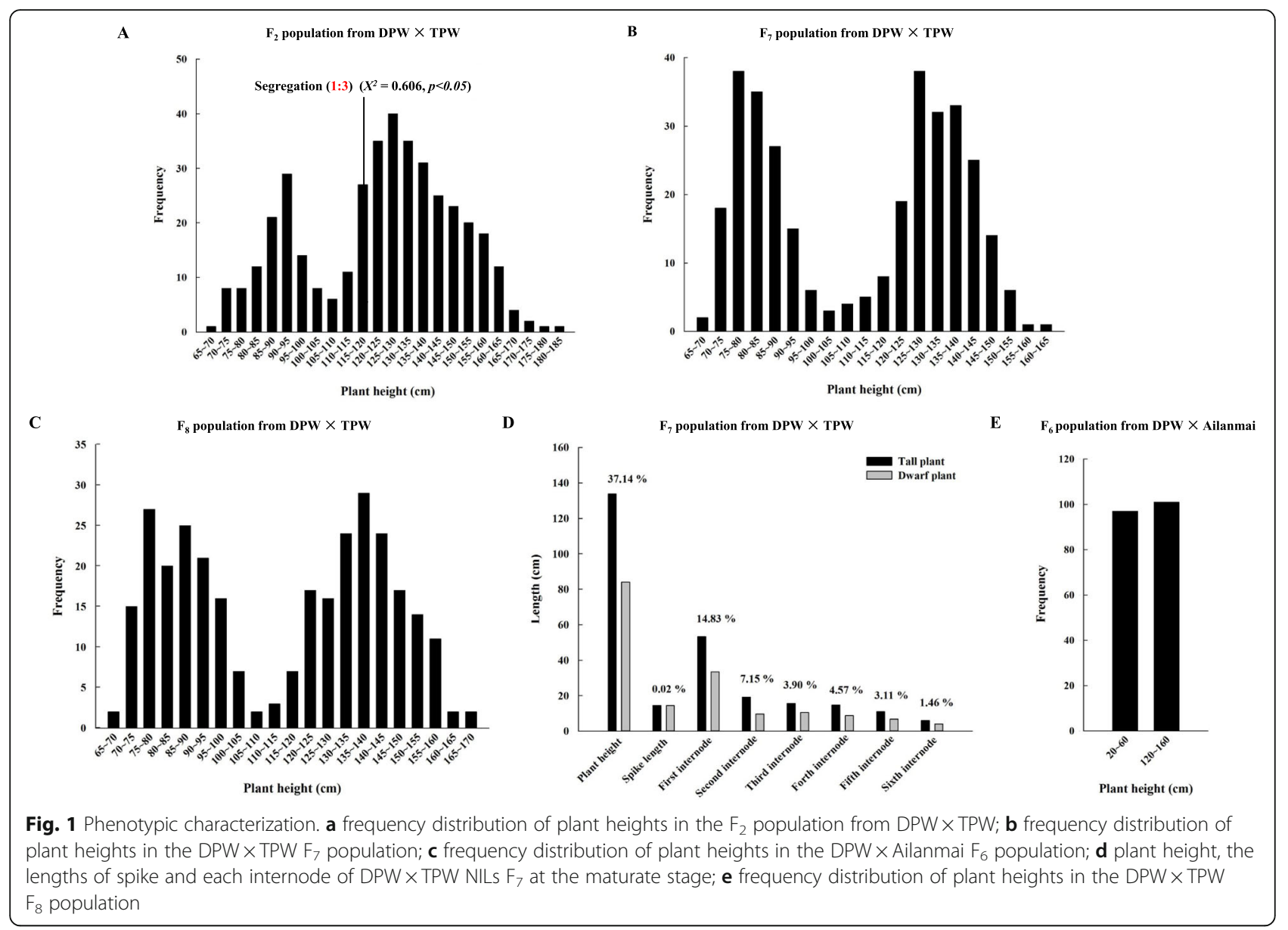

$1.46 \%$ ), but the length of the spike was not affected (Fig. $1 d)$. These results indicate that $R h t-d p$ reduces plant height mainly by restricting elongation of the first and second internodes at the booting stage.

To validate the candidate region of $R h t-d p$ in a different genetic background, an $\mathrm{F}_{6}$ RIL population including 194 lines derived from DPW $\times$ Ailanmai was constructed. The average height of Ailanmai was $100.98 \pm$ $0.37 \mathrm{~cm}$. Ailanmai has a recessive dwarfing gene $R h t 22$, which has an additive effect with $R h t-d p$. The RIL population was grouped into dwarf and tall phenotypes with heights ranging from 20 to $60 \mathrm{~cm}$ and from 120 to 160 $\mathrm{cm}$, respectively (Fig. 1e).

\section{Characterization of Rht-dp in $F_{1}$ plants and $F_{2}$ population} derived from the cross of a pair of NIL

Since genetic analysis suggested that the effect of Rht-dp on reducing plant height was probably influenced by one or more non-allelic loci derived from TPW, a QTL analysis was performed on the $\mathrm{F}_{7}$ RIL population using the wheat $55 \mathrm{~K} \mathrm{SNP}$ array. Beside of a major-locus on 4BS $(R h t-d p)$ derived from DPW caused dwarfism, a micro- locus on 5A derived from TPW heightened plant was detected (unpublished data). To further confirm the information of $R h t-d p$, we measured the plant height of $F_{1}$ plants and $F_{2}$ population derived from the cross of a pair of NIL (D_60 and T_58). The average heights of D_60 and T_58 were $93.52 \pm 1.83 \mathrm{~cm}$ and $159.67 \pm 2.72 \mathrm{~cm}$, respectively; the average plant height of $F_{1}$ was $123.23 \pm$ $2.55 \mathrm{~cm}$. Compared with T_58, $\mathrm{F}_{1}$ plants harbouring $R h t-d p$ showed a reduction in plant height up to $22.82 \%$. The plant heights of $F_{2}$ plants ranged from 65 to 155 $\mathrm{cm}$. According to the frequency distribution of plant height, $F_{2}$ plants were separated into two groups of dwarf and tall phenotypes at $95 \mathrm{~cm}$ (Fig. 2). The dwarf and tall phenotype groups included 62 and 182 lines, respectively, consistent with the expected Mendelian segregation ratio of $1: 3\left(X^{2}=0.021, p<0.05\right)$. Meanwhile, the separated threshold of plant height with $95 \mathrm{~cm}$ was similar to the plant height of D_60 with $93.52 \pm 1.83 \mathrm{~cm}$. These results indicate that the dwarfing gene of Rht-dp should be a single semidominant gene, and further imply that the candidate gene is $R h t-B 1 b$. 


\section{$F_{2}$ population from D_60 $\times T$ T 58}

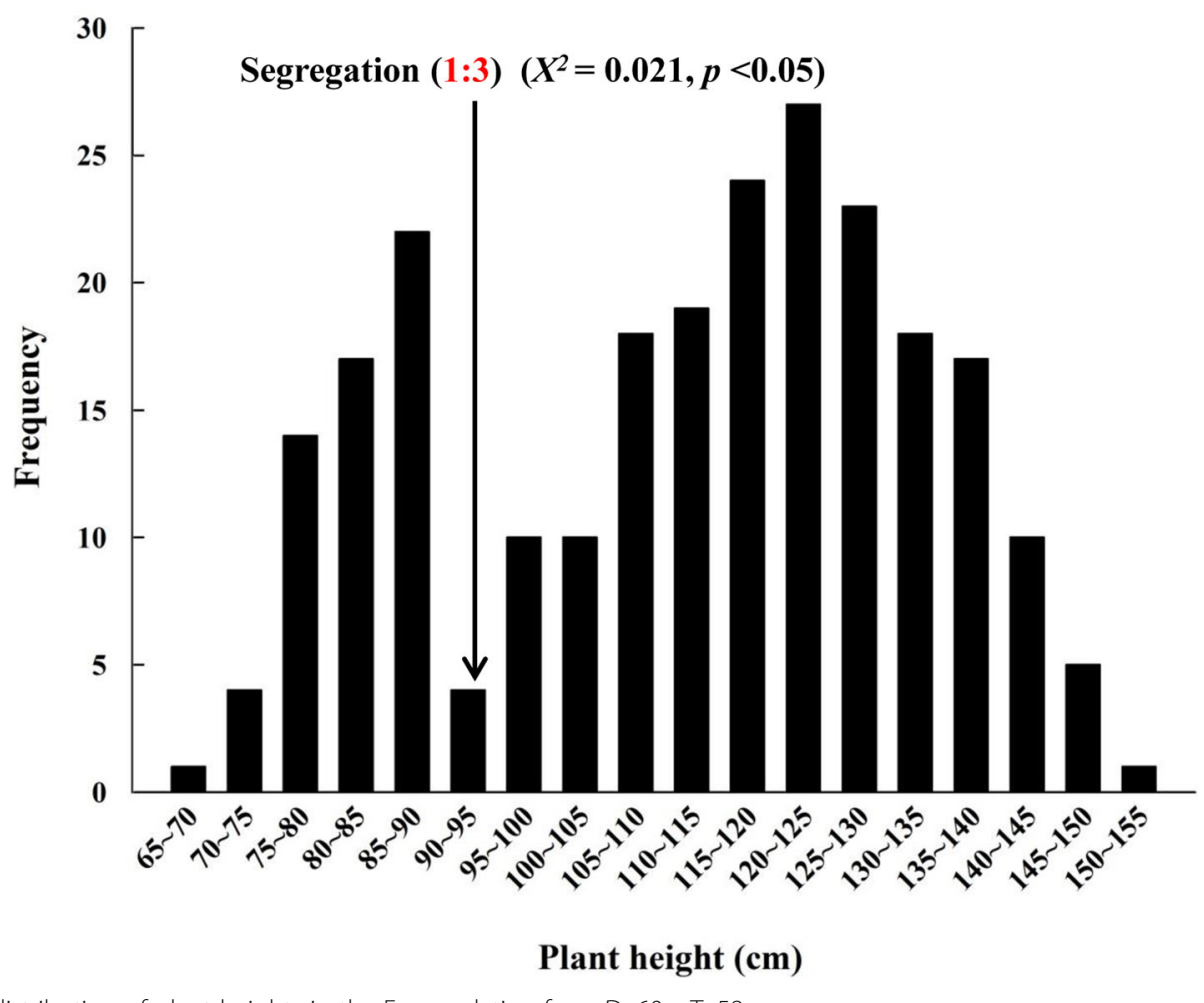

Fig. 2 Frequency distribution of plant heights in the $F_{2}$ population from $D_{-} 60 \times T_{-} 58$

Differences in sequence of Rht-B1 between DPW and TPW To test the implication that the candidate gene of $R h t$ $d p$ is $R h t-B 1 b$ or one of its alleles, the sequences of $R h t$ $B 1$ were cloned from DPW and TPW. Sequence analysis showed that $R h t-B 1$ of DPW is $R h t-B 1 b$, with a single nucleotide change from $C$ to $\mathrm{T}$ at the nucleotide position 190 when compared with Rht-B1a (Fig. 3a) that results in a premature termination codon at amino acid position 64 (Fig. 3b). Although Rht-B1 of TPW did not have this single nucleotide change from $C$ to $T$ at nucleotide position 190, it had a three-nucleotide deletion at nucleotide position 386-388 when compared with Rht-B1a (Fig. 3a), resulting in a serine (S) deletion at amino acid position 129 (Fig. 3b). These results imply that the candidate gene of Rht-dp might be Rht-B1b. An Rht-B1 Indel marker was developed from the threenucleotide deletion of $R h t-B 1$ in TPW for further analysis.

\section{Mapping of Rht-dp}

To confirm that the candidate gene of $R h t-d p$ is $R h t$ $B 1 b$, the Rht-B1Indel marker was first used to determine whether $R h t-B 1$ was tightly linked with $R h t-d p$. Genetic mapping analyses confirmed that the Rht-B1Indel marker completely co-segregated with $R h t-d p$ in three
RIL populations and a $F_{2}$ population derived from a pair of NIL (Fig. 4).

To further confirm that $R h t-B 1 b$ is located in the candidate region of $R h t-d p, 190$ pairs of SSR markers were exploited according to the genome reference of 4BS (Table S2). Fifteen pairs of SSR markers exhibited polymorphism between DPW and TPW, and were linked with $R h t-d p$ in the $\mathrm{F}_{7}$ RIL population. Of them, two SSR markers, Xgpw2994.1 and Xgpw3128.1, were tightly linked with $R h t-d p$ with a genetic distance of 0.6 cM (Fig. 4a; Table S3). Xgpw2994.1 and Xgpw3128.1 were further confirmed as tightly linked markers flanking $R h t-d p$ in the $\mathrm{F}_{2}$ population derived from NIL (Fig. $4 \mathrm{~b}$ ), and the $\mathrm{F}_{6}$ (Fig. 4c) and $\mathrm{F}_{8}$ (Fig. 4d) RIL populations (Table S3).

Based on the gene annotation of wheat 4BS from 29.94 to $31.29 \mathrm{Mbp}$, flanked by Xgpw2994.1 and Xgpw3128.1, there were five potential genes: TraesCS4B01G042700 (encodes a teosinte branched 1 protein), TraesCS4B01G042800 (encodes an uncharacterized protein), TraesCS4B01G042900 (a RING finger protein), TraesCS4B01G043000 (EamA-like transporter family), and TraesCS4B01G043100 (Rht-B1 encodes a DELLA protein) (Fig. 4e). Apart from $R h t-B 1$, sequence difference of other four genes (primers listed in Table 


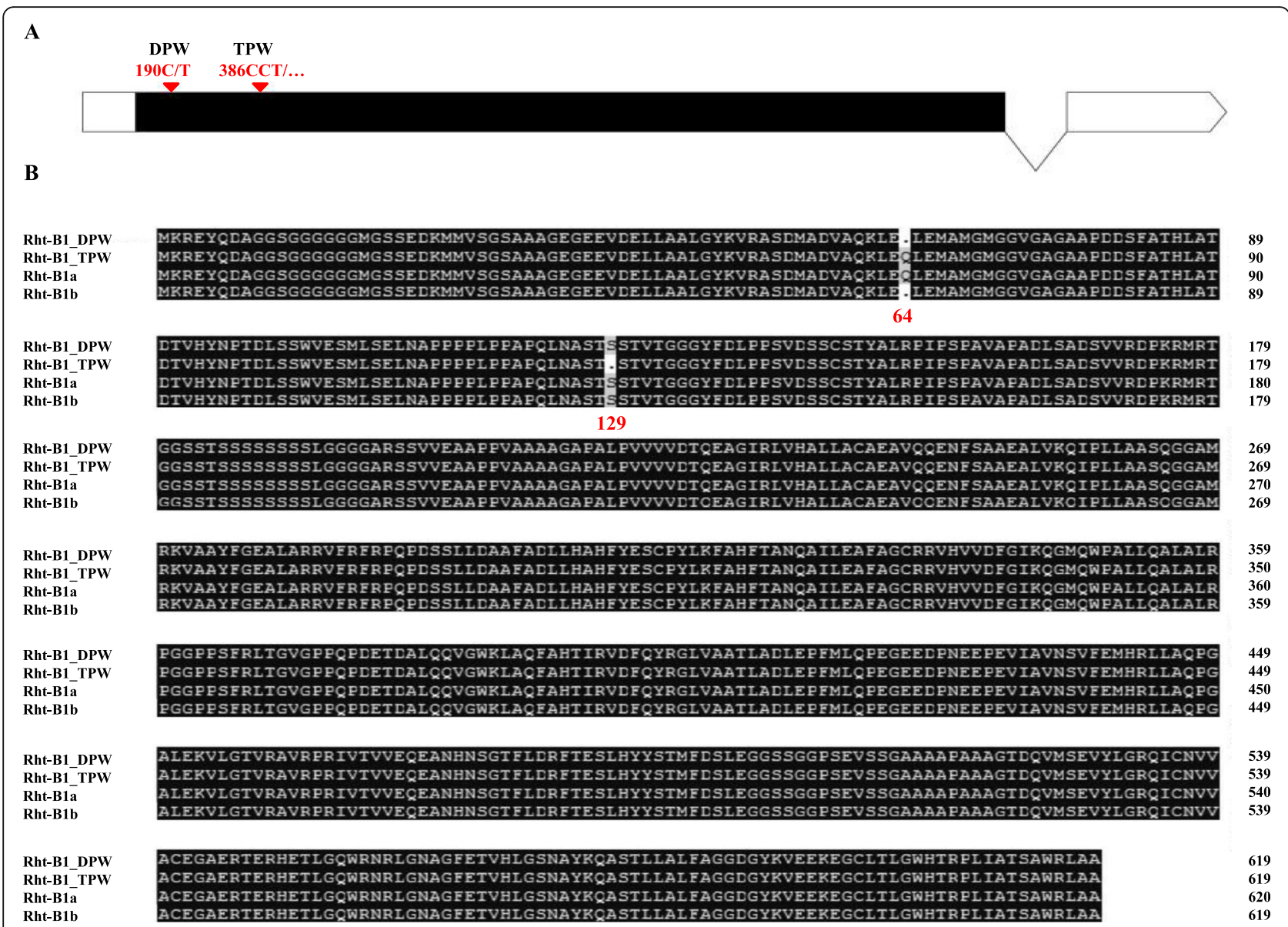

Fig. 3 Sequences of Rht-B1 in DPW and TPW. a: nucleotide mutations of Rht-B1 in DPW and TPW; $\mathbf{b}$ : amino acid mutations of Rht-B1 in DPW and TPW

S4) between DPW and TPW was not found. These results indicate that the candidate gene of $R h t-d p$ should be $R h t-B 1 b$.

\section{Expression patterns of Rht-B1b in DPW}

To confirm that $R h t-B 1 b$ reduces plant height via its effects on elongation of the first and second internodes at the booting stage, the transcriptional patterns of $R h t-B 1 b$ were investigated in different DPW tissues at the jointing, booting, and grain-filling stages. Rht-B1b was mainly expressed in the first and second internodes at the booting stage, and at dramatically higher levels in those tissues than in other tissues at the jointing, booting, and grain-filling stages (Fig. 5).

Allelic variations of Rht-B1 in tetraploid wheat accessions $R h t-B 1 b$ has never been found in spontaneous tetrapolid accession. Since $R h t-B 1 b$ is the candidate gene of $R h t-d p$ in DPW, the haplotypes of $R h t-B 1 b$ in 59 tetraploid wheat accessions were analysed. Among them, five accessions were dwarf phenotypes including two T. turgidum (AS313 and AS2239), two T. polonicum [AS304 (DPW) and IC12196], and one $T$. durum (ZH2237). The 59 sequences cloned from the 59 tetraploid wheat accessions were grouped into eight types. Rht-B1b was only obtained from two $T$. polonicum (DPW and IC12196) accessions; and Rht$B 1 t$ and $R h t-B 1 u$ were only obtained from T. turgidum. Subsp. dicoccon (PI191781) and T. turgidum. Subsp. Turanicum (PI184543), respectively. Of them, five novel types (named Rht-B1q-B1u, respectively) were identified by comparison with Rht-B1a (Fig. 6b). Rht-B1q contained an S deletion at position 129 (S129); Rht-B1r carried a mutation at position 30 (A30S) and an S deletion at position 129 (S129); RhtB1s contained a mutation at position 363 (P363S). Rht-B1t had two mutations at positions 15 (G15R) and 363 (P363S). Rht-B1u also had two mutations at positions 136 (Y136D) and 363 (P363S) (Fig. 6b).

Among these variations, Rht-B1q had the highest frequency (43.9\%). The frequencies of Rht-B1a, Rht-B1b, 
A

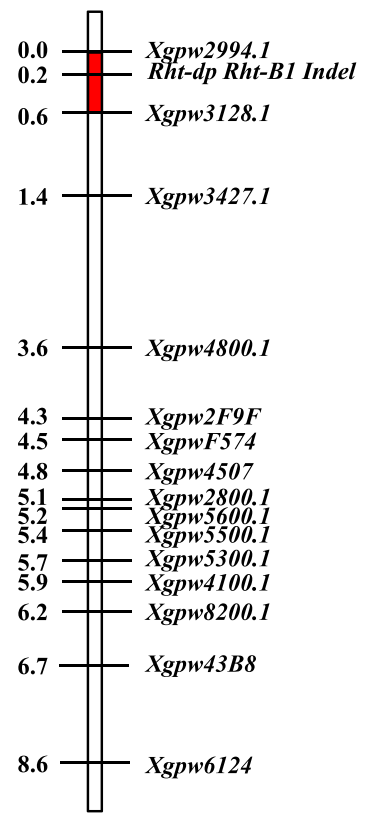

B

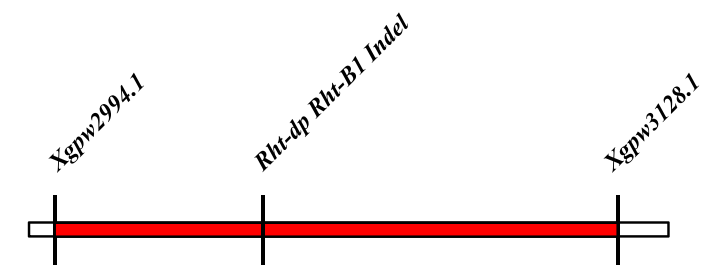

C

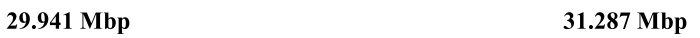

D

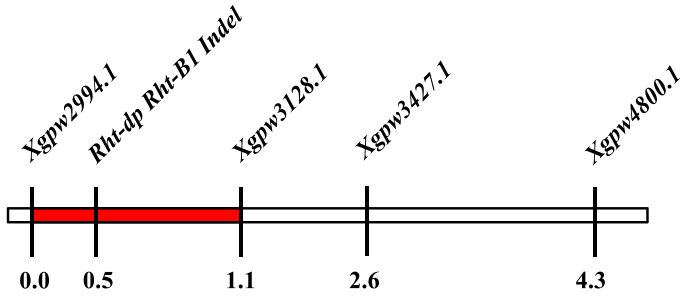

$\mathbf{E}$

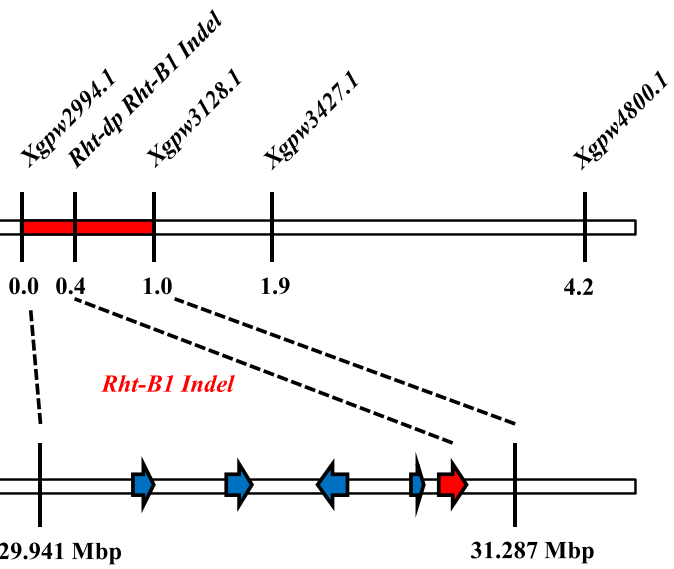

Fig. 4 Mapping of Rht-dp. a: mapping of Rht-dp in the DPW $\times$ TPW RILS F $;$; $\mathbf{b}$ : mapping of Rht-dp in the $F_{2}$ population from D_60 $\times T_{-} 58$; $\mathbf{c}$ : mapping of Rht-dp in DPW $\times$ Ailanmai RILs $F_{6}$; d: mapping of Rht-dp in DPW $\times$ TPW RILs F $;$ i e: candidate genes between SSR markers Xgpw2994.1 and Xgpw3128.1

Rht-B1h, Rht-B1r, Rht-B1s, Rht-B1t, and Rht-B1u were $15.3,3.4,13.6,13.6,6.8,1.7$, and $1.7 \%$, respectively.

\section{Dwarfism-related DEGs induced by DELLA mutant Rht- B1b}

To understand the molecular networks of $R h t-B 1 b$, the DEGs induced by the DELLA mutation $R h t-B 1 b$ in the first internode of two pairs of NILs were investigated. A total of 41 DEGs was obtained, 30 of which were successfully functionally annotated (Table S5). Twentyeight DEGs were further classed into five sub-groups; hormone-related signalling transduction genes, transcription factor genes, cell wall structure-related genes, reactive oxygen-related genes, and nitrogen regulationrelated genes (Table 1). Among the hormone-related signal transduction genes, two brassinolide (BR) signalrelated genes serine carboxypeptidase II-3 (SCP) and cytochrome P450 710A1 (CYP450) were down-regulated; and genes encoding salicylic acid (SA)-binding protein 2 and ARP were up-regulated in the dwarf phenotype. The only down-regulated transcription factor gene was MybAS2. Fifteen DEGs were grouped into cell wall structure-related genes (seven pectin-related genes and eight xylan acetylation-related genes). In the dwarf phenotype, five pectin-related genes [encoding a pectate lyase 15 (PEL15), three subtilisin-like protease (SBT1.7), and an alpha-galactosidase $(\alpha-\mathrm{Gal})]$ involved in pectin modification were down-regulated; while all eight xylan acetylation-related genes, including three GDSL esterase/ lipase genes, two ESKIMO genes, IRX15-L, ALTERED XYLOGLUCAN 4-like (AXY-L), and an uncharacterized acetyltransferase gene were up-regulated. For the reactive oxygen-related genes, plant cysteine oxidase 2 (PCO2) and ASCO were down-regulated; and genes encoding germin-like protein 5-1 (GLP) and blue copper protein $(\mathrm{BCP})$ were up-regulated in the dwarf phenotype. For nitrogen assimilation-related genes, two phosphoenolpyruvate carboxylase kinase 2 (PPCK2) genes and early nodulin (ENOD) were down-regulated; and asparagine synthetase (APS) was up-regulated in the 


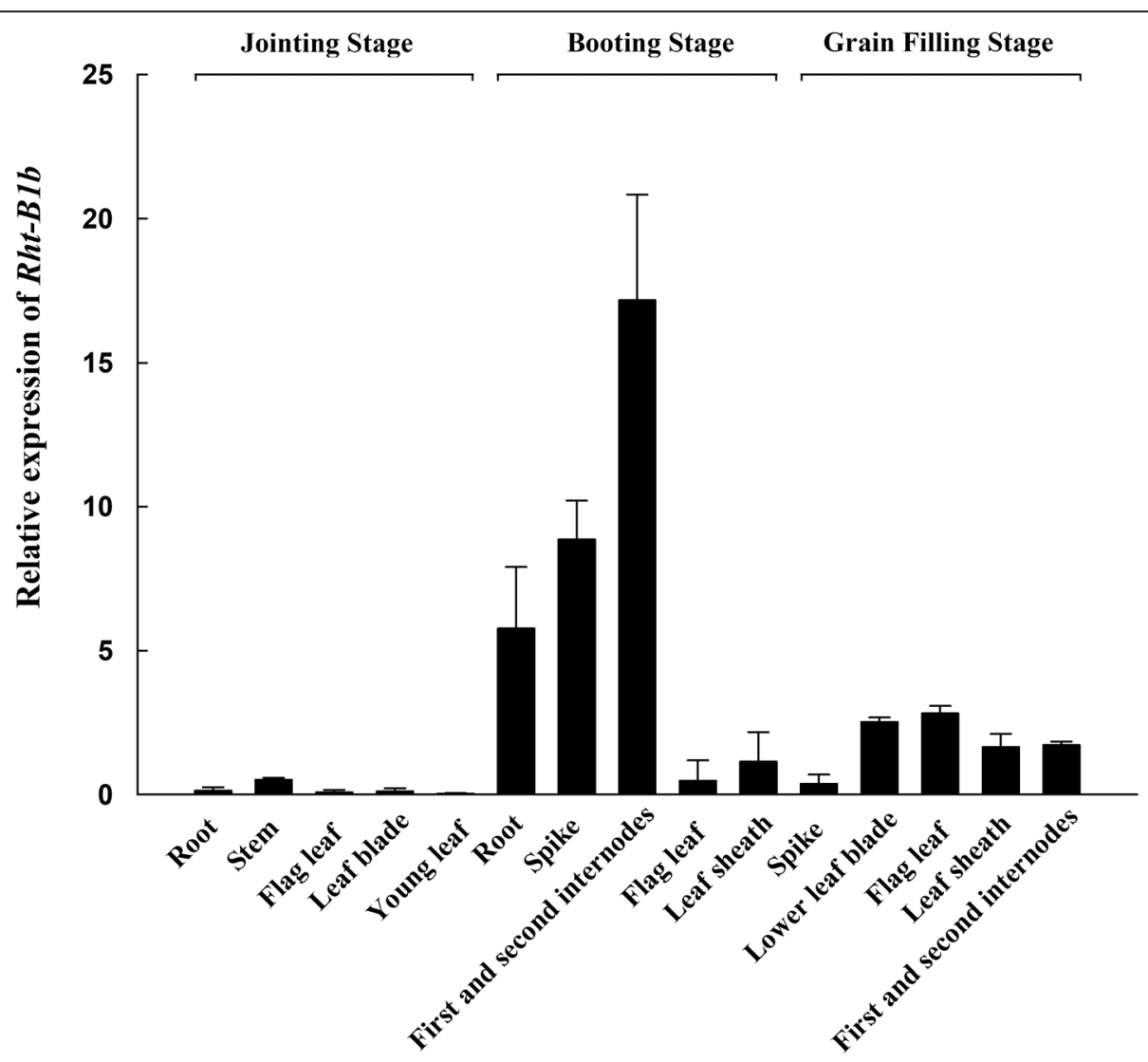

Fig. 5 Expression patterns of Rht-dp in various wheat tissues at jointing, booting, and grain filling stages

dwarf phenotype. We verified the expression of $A R P$ and $A S C O$ in the first and second internodes at the booting stage (Fig. S2).

\section{Discussion}

The GA-insensitive dwarfing gene $R h t-B 1 b$ is the predominant source of the semi-dwarf growth habit of wheat plants grown in parts of Northern Europe [36], the Mid and Lower Yangtze Valley Autumn-sown Spring Wheat Region in China [37], and the Great Plains Hard Winter Wheat Region in the USA [38]. Because Rht-B1b significantly decreases plant height to reduce plant lodging and increase wheat yield [37, 39], it has been introduced into tetraploid wheat $T$. durum for dwarf breeding [28]. However, it is well known that the progenitor of T. polonicum is not Norin 10 or T. durum. Additionally, DPW was originally collected from Tulufan, Xingjiang, China [23]. Thus, the dwarfing gene Rht$d p$ of $T$. polonicum cannot be derived from Norin 10 or T. durum. However, our results show that the candidate gene $R h t-d p$ of DPW is $R h t-B 1 b$. This conclusion is supported by the following evidences: (1) Rht-dp is a single semi-dominant dwarfing gene, as is Rht-B1b [6]. (2) Rht$d p$ and $R h t-B 1 b$ reduce plant height mainly via reducing the length of the first and second internodes (Fig. 1d), and their effects on reducing plant height are similar with $22 \%[18,39]$. (3) The sequence of Rht-B1 of DPW is the same as that of $R h t-B 1 b$ (Fig. 3). (4) Mapping work revealed that the candidate region of $R h t-d p$ was between SSR markers Xgpw2994.1 and Xgpw3128.1 (Fig. $4 \mathrm{~b}-\mathrm{d})$. This region contains five potential genes including $R h t-B 1$ (Fig. 4e); except of Rht-B1, other four genes have no sequence difference between DPW and TPW. (5) The Rht-B1 Indel marker developed based on the sequence difference of Rht-B1 between DPW and TPW is completely co-segregated with $R h t-d p$ in a $\mathrm{F}_{2}$ population derived from NIL and three RIL populations (Fig. 4). In the haplotype analysis, Rht-B1b was only obtained from T. polonicum (Fig. 6a), implying that it might originate from this species, or might be introduced into T. polonicum from other unknown species but not $T$. aethiopicum and T. durum.

In wheat, Rht-B1b encodes a DELLA mutant protein resembling the SLRL1 protein. Its accumulation represses GA-regulated growth and developmental responses and causes the typical semi-dwarf phenotype [6, 40]. DELLA not only regulates the expression of downstream genes but also interacts with DNA-binding transcription factors. Our transcript analysis identified 28 DEGs regulated by the DELLA mutant $R h t-B 1 b$ involved 


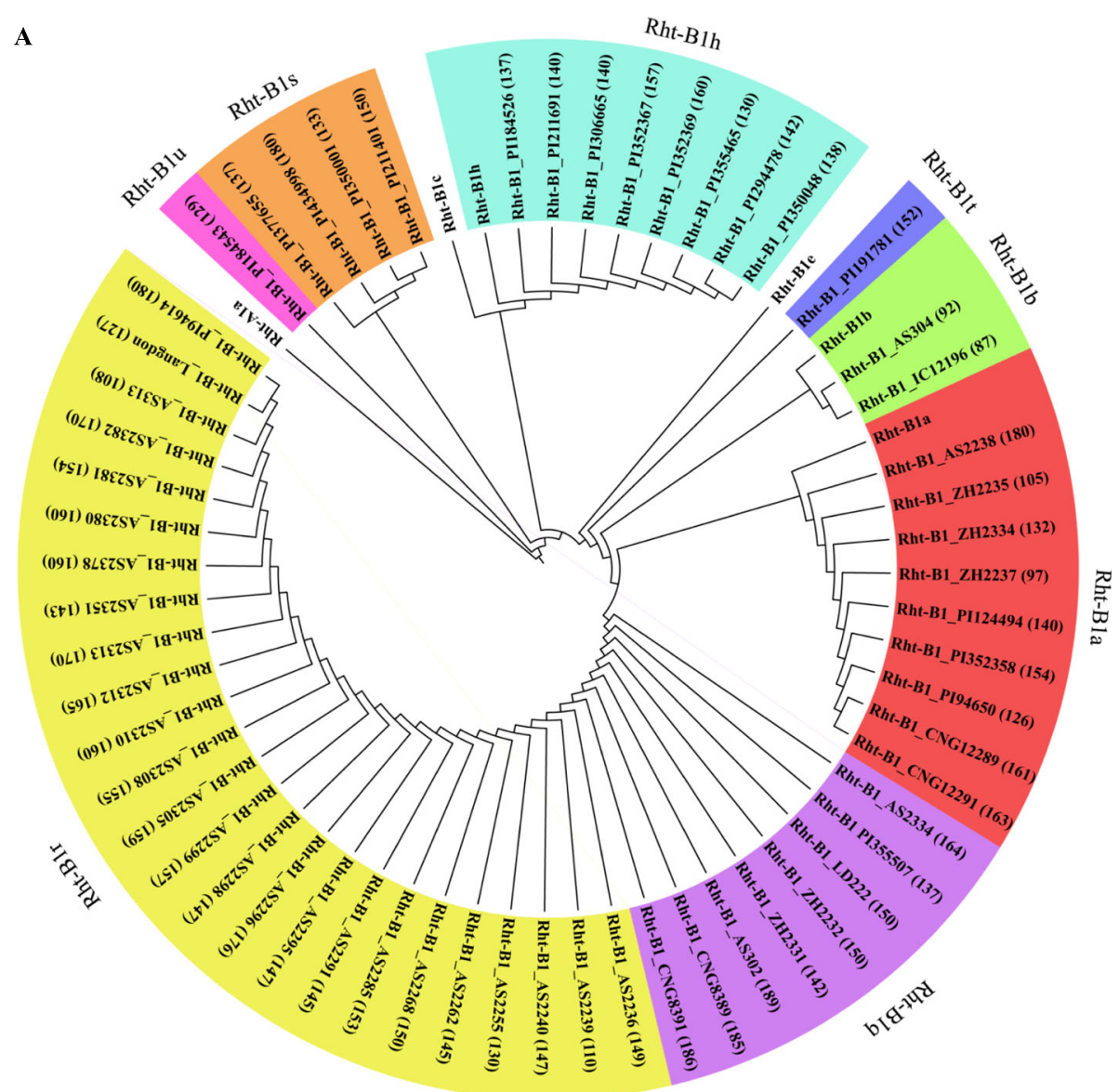

B

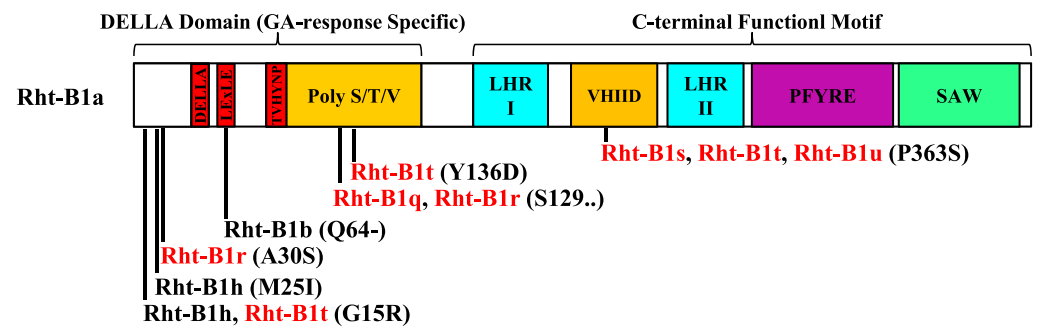

Fig. 6 Haplotype analysis of Rht-B1 in 59 tetraploid wheat accessions. a phylogenetic relationship of Rht-B1 alleles; $\mathbf{b}$ nonsynonymous mutations in Rht-B1

in the processes of nitrogen assimilation, oxidationreduction, modification of the cell wall components and structures, and hormone-related signal transduction (Table 1). However, this list of DEGs only slightly overlaps with those identified in previous studies, suggesting that the effects of DELLA on transcription depend on the species, organ, and developmental context [41-44]. Since $R h t-B 1 b$ is mainly expressed in the first and second internodes (Fig. 5) to dramatically reduce their lengths at the booting stage in DPW (Fig. 1d), we explored the molecular network of $R h t-d p$ by conducting a transcript analysis of the first and second internodes at the booting stage.

The control of plant growth and development by DELLA is dependent on GA-regulated growth and developmental responses [44-46]. However, we did not find genes involved in GA metabolism among the DEGs in this study. Instead, the DEGs identified in this study included auxin-, SA- and BR-related genes (Table 1). These results suggested that GA interacts with these hormones [46]. DELLA can directly trigger the expression of auxin- and BR-related genes to affect plant 
Table 1 Dwarfism-related DEGs induced by DELLA mutant Rht-dp

\begin{tabular}{|c|c|c|c|}
\hline \multirow[t]{2}{*}{ Gene ID } & \multirow[t]{2}{*}{ Description } & \multicolumn{2}{|c|}{ Fold change of transcript } \\
\hline & & D_60/T_58 & D_33/T_35 \\
\hline \multicolumn{4}{|c|}{ Hormone-related signaling transduction genes } \\
\hline TraesCS2B01G157100 & Serine carboxypeptidase II-3 & -32 & -20 \\
\hline TraesCS3B01G167400 & Cytochrome P450 710A1 & -25 & -18 \\
\hline TraesCS2B01G471800 & Salicylic acid-binding protein 2 & 28 & 39 \\
\hline TraesCS4B01G070300 & Auxin-repressed $125 \mathrm{kDa}$ protein & 12 & 15 \\
\hline \multicolumn{4}{|l|}{ Transcription factor } \\
\hline TraesCS1B01G055200 & Myb-related protein MYBAS2 & -13 & -26 \\
\hline \multicolumn{4}{|c|}{ Cell wall structure-related genes } \\
\hline \multicolumn{4}{|l|}{ Pectin-related genes } \\
\hline TraesCS2A01G016500 & Pectate lyase 15 & -17 & -29 \\
\hline TraesCS4A01G237500 & Subtilisin-like protease SBT17 & -20 & -22 \\
\hline TraesCS4B01G077600 & Subtilisin-like protease SBT17 & -29 & -17 \\
\hline TraesCS6A01G339400 & Subtilisin-like protease SBT17 & -14 & -12 \\
\hline TraesCS6B01G332900 & Alpha-galactosidase & -16 & -11 \\
\hline TraesCS1B01G249000 & (1-3,1-4)-beta-D-glucanase & 21 & 28 \\
\hline TraesCS2A01G341400 & Sugar transport protein 5 & 11 & 14 \\
\hline \multicolumn{4}{|c|}{ Xylan acetylation-related genes } \\
\hline TraesCS3A01G258100 & GDSL esterase/lipase & 15 & 11 \\
\hline TraesCS3B01G290800 & GDSL esterase/lipase & 13 & 10 \\
\hline TraesCS7B01G250700 & GDSL esterase/lipase & 13 & 23 \\
\hline TraesCS4A01G110000 & ESKIMO 1 & 14 & 10 \\
\hline TraesCS4B01G194100 & ESKIMO 1 & 17 & 10 \\
\hline TraesCS6A01G131900 & IRX15-like & 13 & 11 \\
\hline TraesCS7A01G191700 & ALTERED XYLOGLUCAN 4-like & 17 & 11 \\
\hline TraesCSU01G204900 & Uncharacterized acetyltransferase & 28 & 16 \\
\hline \multicolumn{4}{|c|}{ Reactive oxygen-related genes } \\
\hline TraesCS5A01G025200 & Plant cysteine oxidase 2 & -11 & -15 \\
\hline TraesCS7A01G459400 & L-ascorbate oxidase homolog & -34 & -51 \\
\hline TraesCS3A01G165500 & Germin-like protein 5-1 & 16 & 22 \\
\hline TraesCS6A01G315800 & Blue copper protein & 13 & 12 \\
\hline \multicolumn{4}{|c|}{ Nitrogen regulation-related genes } \\
\hline TraesCS6A01G375800 & Phosphoenolpyruvate carboxylase kinase 2 & -12 & -20 \\
\hline TraesCS6B01G413500 & Phosphoenolpyruvate carboxylase kinase 2 & -12 & -15 \\
\hline TraesCS7A01G091800 & Early nodulin-93 & -40 & -12 \\
\hline TraesCS3B01G385400 & Asparagine synthetase & 11 & 12 \\
\hline
\end{tabular}

growth $[47,48]$. For example, the expressions of SCP and CYP450 (both grouped into BR-related genes) were dramatically down-regulated by the DELLA mutation Rht$B 1 b$ to potentially cause dwarfism in DPW (Table 1 ), because the expression of SCP positively affects plant growth [49]. Auxin represses the expression of $A R P$ genes [50, 51]. In a previous study, overexpression of an ARP of Brassica rapa caused a reduction in vegetative growth [50]. Auxin also modulates the expression of ASCO, which encodes a crucial enzyme that produces oxidative molecules, including $\mathrm{H}_{2} \mathrm{O}_{2}$ [52]. Overexpression of an ASCO in cotton enhanced the accumulation of $\mathrm{H}_{2} \mathrm{O}_{2}$ and promoted cell elongation, whereas suppression of an ASCO in tobacco and Arabidopsis inhibited stem cell growth [53]. Our results show that the DELLA mutation $R h t-B 1 b$ resulted in dramatically up-regulated $A R P$ and downregulated $A S C O$ in DPW (Table 1). Auxin-induced growth inhibition is accompanied by decreased levels 
of reactive oxygen species [54]. Thus, the accumulation of the DELLA mutant protein regulated via auxin-mediated signal transduction may reduce the contents of reactive oxygen species such as $\mathrm{H}_{2} \mathrm{O}_{2}$ [41], thereby limiting cell expansion to cause dwarfism in DPW.

In rice, over-expression of an early nodulin gene resulted in improved nitrogen-use efficiency and increased nitrogen assimilation [55]. In $\mathrm{C}_{3}$ plants, nitrogen assimilation is positively correlated with phosphoenolpyruvate carboxylase (PEPC) phosphorylation [56, 57], which is catalysed by phosphoenolpyruvate carboxylase kinase (PPCK). The extent of phosphorylation is largely determined by PPCK activity, which is controlled by the level of PPCK transcripts [56, 58, 59]. A reduction in PEPC activity leads to serious stunting of growth [60]. Our results showed that the DELLA mutation $R h t-B 1 b$ led to significant down-regulation of early nodulin and two PPCKs in DPW (Table 1). Thus, decreased nitrogen assimilation and PPCK activity may decrease the activity of PEPC $[43,59]$ to cause dwarfism in DPW.

The hemicellulose xylan and pectins are two abundant polysaccharides in the plant cell wall [61]. Their modifications, such as methylesterification and acetylation, have been proposed to influence cell wall architecture and function, causing various plant growth phenotypes [61-64]. Our results showed that the DELLA mutation $R h t-B 1 b$ led to significant down-regulation of the expression of several pectin-related genes, including $P E L$, three $S B T s$, and $\alpha$-Gal (Table 1). Decreases in the transcript levels of these genes may lead to the repression of pectin degradation and the accumulation of deesterified pectin [63], enhanced pectin methylesterase activity to stiffen the cell wall [65], and reduced adherence of pectin to the cell wall [66]. Thus, the DELLA mutation Rht-B1b may result in modifications of pectin that limit cell wall loosening and inhibit cell elongation, thereby causing dwarfism in DPW.

Many studies have reported that either excess or inadequate acetylation of xylan disrupts the cell wall structure, thereby causing dwarfism in plants $[67,68]$. Our results show that the DELLA mutation $R h t-B 1 b$ upregulated eight xylan acetylation-related genes, including three GDSL esterase/lipase genes, two ESKIMO genes, IRX15-L, $A X Y-L$, and an uncharacterized acetyltransferase gene (Table 1). ESKIMO and AXY-L are xylan acetyltransferases, and IRX-L is involved in synthesis of the

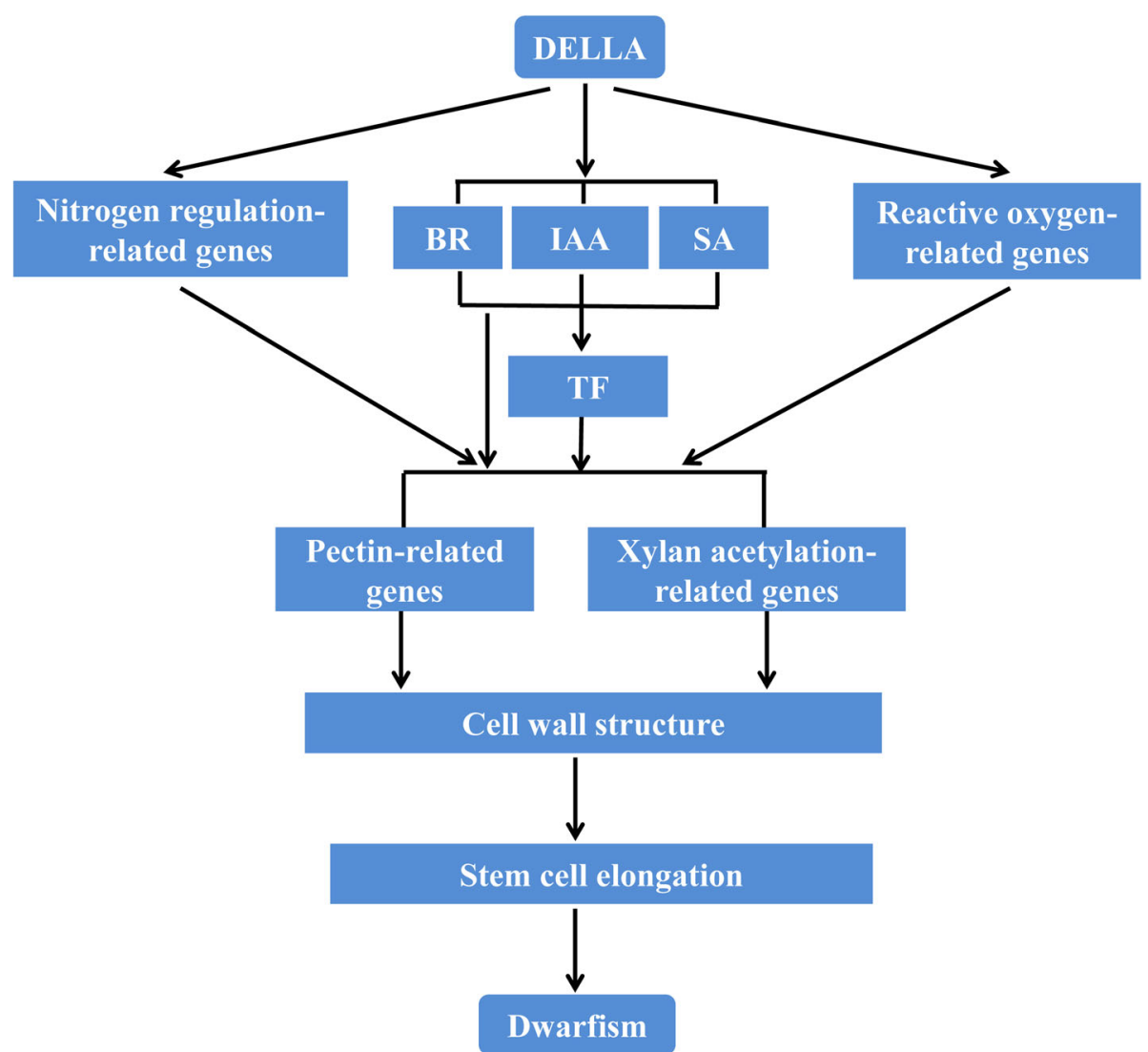

Fig. 7 Molecular network model of the DELLA mutation Rht-dp in DPW 
xylan backbone [61, 67-70]. A specific interaction between acetyltransferases and xylan backbone biosynthetic enzymes may repress acetylation of adjacent residues $[68,70]$. Therefore, even though the transcript levels of ESKIMO, IRX15-L, AXY-L and IRX-L were upregulated (Table 1), the acetylation of xylan might be decreased. GDSL esterase/lipase is a xylan deacetylation enzyme [64]. The DELLA mutation $R h t-B 1 b$ resulted in up-regulated expression of GDSL esterase/lipase, leading to enhance xylan deacetylation. Therefore, the DELLA mutation Rht-B1b may reduce acetylation of xylan to limit cell wall loosening and inhibit cell elongation, causing dwarfism in DPW.

A model summarizing how the DELLA mutation Rht$d p$ causes dwarfism in DPW is proposed (Fig. 7). Whether the DELLA mutation $R h t-B 1 b$ regulates the pathway of hormones, reactive oxygen species, and nitrogen assimilation, it ultimately affects the cell wall structure to limit cell wall loosening and inhibit cell elongation, thereby causing dwarfism in DPW.

\section{Conclusion}

In summary, our results indicated that the semidwarfing gene Rht-dp is the "Green Revolution" gene $R h t-B 1 b$. It regulates pathways related to hormones, reactive oxygen species, and nitrogen assimilation to modify the cell wall structure, and then limits cell wall loosening and inhibits cell elongation, thereby causing dwarfism in DPW.

\section{Supplementary Information}

The online version contains supplementary material available at https://doi. org/10.1186/s12864-021-07367-x.

Additional file 1: Fig. S1. The plant height of DPW, TPW, and DPW $\times$ TPW F 1 .

Additional file 2: Fig. S2. Relative expression of $A R P$ and ASCO in the first and second internodes at the booting stage.

Additional file 3: Table S1. The information of 59 tetraploid wheat accessions.

Additional file 4: Table S2. The information of SSR primers on 4BS chromosome.

Additional file 5: Table S3. Genotype data of RIL populations and the $F_{2}$ population from D_60 $\times$ T_58.

Additional file 6: Table S4. Gene-specific primers for Rht-dp candidate genes in DPW and TPW

Additional file 7: Table S5. The information of Dwarfism-related DEGs induced by DELLA mutant Rht-dp.

\section{Abbreviations}

BR: Brassinolide; cM: centimorgan; DEGs: Differentially expressed genes; DPW: Dwarf polish wheat; FPKM: Fragments per kilobase of transcript per million mapped reads; GA: Gibberellin; Jianyangailanmai: Ailanmai; LOD: Logarithm of odds; NIL: Near-isogenic line; qPCR: Quantitative real-time PCR; RIL: Recombinant inbred line; RNA-seq: RNA sequencing; SA: Salicylic acid; TPW: Tall polish wheat

\section{Acknowledgements}

We thank the professor Lianquan Zhang (Sichuan Agricultural University, China) who provided the grain of tetraploid wheat accessions for haplotype analysis.

\section{Authors' contributions}

$S C, X X, J L, Y W$ and $Y Z$ designed the research and wrote the manuscript; SC, QY, XZ and XX performed the experiments; SC, XF, JZ, LS, HK, HZ and YW performed the data analysis and revised the manuscript. Thel author(s) read and approved the final manuscript.

\section{Funding}

This work was supported by the National Natural Science Foundation of China (No 31671688), and the Bureau of Science and Technology of Sichuan Province, China.

\section{Availability of data and materials}

All data generated or analyzed during this study were included in this article and the supplementary files.

\section{Ethics approval and consent to participate}

The DPW and TPW lines were originally collected from Tulufan, Xinjiang province, China, by Prof. Chi Yen and Junliang Yang (Sichuan Agricultural University, China) in the 1980s. No permission was necessary to collect this sample. Professor Chi Yen undertook the formal identification of the sample. The voucher specimen and the seed are deposited in the Triticeae Research Institute, Sichuan Agricultural University, Chengdu, Sichuan, China. Collection of the dwarf Polish wheat complied with the institutional, national and international guidelines.

Consent for publication

Not applicable.

\section{Competing interests}

The authors declare that they have no conflicts of interest.

\section{Author details}

${ }^{1}$ Triticeae Research Institute, Sichuan Agricultural University, Wenjiang, Chengdu 611130, Sichuan, China. ${ }^{2}$ College of Resources, Sichuan Agricultural University, Wenjiang, Chengdu 611130, Sichuan, China. ${ }^{3}$ Crop Research Institute, Sichuan Academy of Agricultural Sciences, Chengdu 610066, Sichuan, China.

Received: 14 August 2020 Accepted: 1 January 2021

Published online: 19 January 2021

\section{References}

1. Gale MD, Youssefian S, Russell GE. Dwarfing genes in wheat. Progress in. Plant Breed. 1985;1:1-35.

2. Flintham JE, Börner A, Worland AJ, Gale MD. Optimizing wheat grain yield: effects of Rht (gibberellin-insensitive) dwarfing genes. J Agri Sci. 1997;128(1): $11-25$.

3. Youssefian S, Kirby EJM, Gale MD. Pleiotropic effects of the GA- insensitive Rht dwarfing genes in wheat. 2. Effects on leaf, stem, ear and floret growth. Field Crop Res. 1992;28(3):191-210.

4. Hedden P. The genes of the green revolution. Trends Genet. 2003:19(1):5-9.

5. Hong Z, Ueguchi-Tanaka M, Shimizu-Sato S, Inukai Y, Fujioka S. Loss- offunction of a rice brassinosteroid biosynthetic enzyme, C-6 oxidase prevents the organized arrangement and polar elongation of cells in the leaves and stem. Plant J. 2002;32(4):495-508.

6. Peng JR, Richards DE, Hartley NM, Murphy GP, Devos KM, Flintham JE, Beales J, Fish L, Worland AJ, Pelica F, Sudhakar D, Christou P, Snape JW, Gale MD, Harberd NP. 'Green Revolution' genes encode mutant gibberellin response modulators. Nature. 1999:400(6741):256.

7. Sasaki A, Ashikari M, Ueguchi-Tanaka M, Itoh H, Nishimura A, Swapan D, Ishiyama K, Saito T, Kobayashi M, Khush GS, Kitano H, Matsuoka M. Green revolution: a mutant gibberellin- synthesis gene in rice. Nature. 2002; 416(6882):701-2

8. Chen SL, Gao RH, Wang HY, Wen MX, Xiao J, Bian NF, Zhang RQ, Hu WJ, Cheng SH, Bie TD, Wang XU. Characterization of a novel reduced height 
gene (Rht23) regulating panicle morphology and plant architecture in bread wheat. Euphytica. 2015;203(3):583-94.

9. Ellis MH, Rebetzke GJ, Azanza F, Richards RA, Spielmeyer W. Molecular mapping of gibberellin-responsive dwarfing genes in bread wheat. Theor Appl Genet. 2005;111(3):423-30.

10. Kang HY, Lin LJ, Song ZJ, Yuan JY, Zhong MY, Zhang HQ, Fan X, Sha LN, Wang $Y, X u$ LL, Zeng J, Zhou YH. Identification, fine mapping and characterization of $R h t-d p$, a recessive wheat dwarfing (reduced height) gene derived from Triticum polonicum. Genes Genom. 2012;34(5):509-15.

11. Mo Y, Vanzetti LS, Hale I, Spagnolo EJ, Guidobaldi F, Al-Oboudi J, Dubcovsky J. Identification and characterization of Rht25, a locus on chromosome arm $6 \mathrm{AS}$ affecting wheat plant height, heading time, and spike development. Theor Appl Genet. 2018:131(10):2021-35.

12. Pearce $S$, Saville R, Vaughan SP, Chandler PM, Wilhelm EP, Sparks CA, Hedden P. Molecular characterization of Rht-1 dwarfing genes in hexaploid wheat. Plant Physiol. 2011;157(4):1820-31.

13. Vikhe P, Patil RM, Chavan A, Oak MD, Tamhankar SA. Mapping gibberellinsensitive dwarfing locus Rht18 in durum wheat and development of SSR and SNP markers for selection in breeding. Mol Breeding. 2017:37(3):28.

14. Watanabe N. Triticum polonicum IC ${ }^{12196}$ : a possible alternative source of GA3-insensitive semi-dwarfism. Cereal Res Commun. 2004;32(4):429-34.

15. Watanabe N. Genetic mapping of the genes and development of nearisogenic lines in durum wheat. EWAC Newsletters; 2008. p. 27-8.

16. Würschum T, Langer SM, Longin CFH, Tucker MR, Leiser WL. A modern green revolution gene for reduced height in wheat. Plant J. 2017;92(5): 892-903.

17. Gasperini D, Greenland A, Hedden P, Dreos R, Harwood W, Griffiths S. Genetic and physiological analysis of Rht8 in bread wheat: an alternative source of semi-dwarfism with a reduced sensitivity to brassinosteroids. J Exp Bot. 2012;63(12):6760.

18. Rebetzke GJ, Ellis MH, Bonnett DG, Mickelson B, Condon AG, Richards RA. Height reduction and agronomic performance for selected gibberellinresponsive dwarfing genes in bread wheat (Triticum aestivum L). Field Crop Res. 2012;126:87-96.

19. Haque MA, Martinek P, Kobayashi S, Kita I, Ohwaku K, Watanabe N, Kuboyama T. Microsatellite mapping of genes for semi-dwarfism and branched spike in Triticum durum Desf var ramosoobscurum Jakubz "Vetvistokoloskaya". Genet Resour Crop Ev. 2012;59(5):831-7.

20. Konzak CF. Mutations and mutation breeding. Wisconsin, American. In: Heyne EG, editor. wheat and wheat improvement 2nd Edition American Society of Agronomy; 1987. p. 428-43.

21. Peng ZS, Li X, Yang ZJ, Liao ML. A new reduced height gene found in the tetraploid semi-dwarf wheat landrace Aiganfanmai. Genet Mol Res. 2011; 10(4):2349-57.

22. Wiwart M, Suchowilska E, Kandler W, Sulyok M, Groenwald P, Krska R. Can polish wheat (Triticum polonicum L) be an interesting gene source for breeding wheat cultivars with increased resistance to Fusarium head blight. Genet Resour Crop Ev. 2013;60(8):2359-73.

23. Liu GX, Zhou YH, Zheng YL, Yang RW, Ding CB. The reaction of hormone gibberellic acid in dwarfing polish wheat (Triticum polonicum) from Tulufan, Xinjiang. J Sichuan Agric Univ. 2002;20:81-3.

24. Wang Y, Xiao X, Wang XL, Zeng J, Kang HY, Fan X, Sha LN, Zhang HQ, Zhou $\mathrm{YH}$. RNA-Seq and iTRAQ reveal the dwarfing mechanism of dwarf polish wheat (Triticum polonicum L). Int J Bio Sci. 2016;12(6):653.

25. Bazhenov MS, Divashuk MG, Amagai Y, Watanabe N, Karlov Gl. Isolation of the dwarfing Rht-B1p (Rht17) gene from wheat and the development of an allele-specific PCR marker. Mol Breeding. 2015;35(11):1-8.

26. Wen W, Deng QY, Jia HY, Wei LZ, Wei JB, Wan HS, Yang LM, Cao WJ, Ma $Z Q$. Sequence variations of the partially dominant DELLA gene Rht-B1C in wheat and their functional impacts. J Exp Bot. 2013;64(11):3299-312.

27. Reitz LP, Salmon SC. Origin, history, and use of Norin 10 wheat 1. Crop Sci. 1968:8:686-9.

28. Quick JS, Miller JD, Donnelly BJ. Cando North Dakota's first Semidwarf durum. North Dakota Farm Res. 1976;33:15-8.

29. Börner A, Plaschke J, Korzun V, Worland AJ. The relationships between the dwarfing genes of wheat and rye. Euphytica. 1996;89(1):69-75.

30. Haque MA, Martinek P, Watanabe N, Kuboyama T. Genetic mapping of gibberellic acid-sensitive genes for semi-dwarfism in durum wheat. Cereal Res Commun. 2011;39(2):171-8.

31. Beier $S$, Thiel $T$, Münch $T$, Scholz U, Mascher M. MISA-web: a web server for microsatellite prediction. Bioinformatics. 2017;33(16):2583-5.
32. Thiel T, Michalek W, Varshney RK, Graner A. Exploiting EST databases for the development and characterization of gene-derived SSR-markers in barley (Hordeum vulgare L). Theor Appl Genet. 2003;106(3):411-22.

33. Kosambi DD. The estimation of map distances from recombination values. Ann Hum Genet. 1943;12(1):172-5.

34. Wang $Y$, Wang $X L$, Gu MX, Kang HY, Zeng J, Fan $X$, Sha LN, Yu KF, Zhou YH. Cloning and characterization of four novel SnRK2 genes from Triticum polonicum. Biol Plantarum. 2015;59(2):211-9.

35. Trapnell C, Roberts A, Goff L, Pertea KGD, Kelley DR, Pimentel H, Salzberg SL, Rinn JL, Pachter L. Differential gene and transcript expression analysis of RNA-seq experiments with TopHat and Cufflinks. Nat Protoc. 2012;7(3):562.

36. Knopf C, Becker HC, Ebmeyer E, Korzun V. Occurrence of three dwarfing Rht genes in German winter wheat varieties. Cereal Res Commun. 2008;36(4):553-60.

37. Zhang XK, Yang SJ, Zhou Y, He ZH, Xia XC. Distribution of the Rht-B1b, Rht$D 1 b$ and Rht8 reduced height genes in autumn-sown Chinese wheats detected by molecular markers. Euphytica. 2006;152(1):109-16.

38. Guedira M, Brown-Guedira G, Van Sanford DA, Sneller C, Souza E, Marshall D. Distribution of Rht genes in modern and historic winter wheat cultivars from the eastern and Central USA. Crop Sci. 2010;50(5):1811-22.

39. Liu Y, Zhang J, Hu YG, Chen J. Dwarfing genes Rht4 and Rht-B1b affect plant height and key agronomic traits in common wheat under two water regimes. Field Crop Res. 2017;204(204):242-8.

40. Van De Velde K, Ruelens P, Geuten K, Rohde A, Van Der Straeten D. Exploiting DELLA signaling in cereals. Trends Plant Sci. 2017;22(10):880-93.

41. Achard P, Renou JP. BerthoméR, Harberd NP, Genschik P. plant DELLAs restrain growth and promote survival of adversity by reducing the levels of reactive oxygen species. Curr Biol. 2008;18(9):656-60.

42. Carrera E, Ruiz-Rivero O, Peres LE, Atares A, Garcia-Martinez JL. Characterization of the procera tomato mutant shows novel functions of the SIDELLA protein in the control flower morphology, cell division and expansion, and the auxin-signaling pathway during fruit-set and development. Plant Physiol. 2012;160(3):1581-96.

43. Li S, Tian YH, Wu K, Ye YF, Yu JP, Zhang JQ, Liu Q, Hu MY, Li H, Tong YP, Harberd NP, Fu XD. Modulating plant growth-metabolism coordination for sustainable agriculture. Nature. 2018;560(7720):595-600.

44. Locascio A, Blázquez MA, Alabadí D. Genomic analysis of DELLA protein activity. Plant Cell Physiol. 2013;54(8):1229-37.

45. Cao DN, Cheng H, Wu W, Soo HM, Peng JR. Gibberellin mobilizes distinct DELLA-dependent transcriptomes to regulate seed germination and floral development in Arabidopsis. Plant Physiol. 2006;142(2):509-25.

46. Claeys H, De Bodt S. InzéD. Gibberellins and DELLAs: central nodes in growth regulatory networks. Trends Plant Sci. 2014;19(4):231-9.

47. Bai MY, Shang JXOE, Fan M, Bai Y, Zentella R, Suin TP, Wang ZY. Brassinosteroid gibberellin and phytochrome impinge on a common transcription module in Arabidopsis. Nat Cell Biol. 2012;14(8):810-7.

48. Willige BC, Losno E, Richter R, Zourelidou M, Schwechheimer C. Gibberellin regulates PIN-FORMED abundance and is required for auxin transportdependent growth and development in Arabidopsis thaliana. Plant Cell. 2011;23(6):2184-95.

49. Zhou AF, Li J. Arabidopsis BRS1 is a secreted and active serine carboxypeptidase. J Biol Chem. 2005;280(42):35554-61.

50. Lee J, Han CT, Hur Y. Molecular characterization of the Brassica rapa auxinrepressed, superfamily genes, BrARP1 and BrDRM1. Mol Biol Rep. 2013;40(1): 197-209.

51. Park S, Han KH. An auxin-repressed gene (RpARP) from black locust (Robinia pseudoacacia) is posttranscriptionally regulated and negatively associated with shoot elongation. Tree Physiol. 2003;23(12):815-23.

52. Li R, Xin S, Tao CC, Jin X, Li HB. Cotton ascorbate oxidase promotes cell growth in cultured tobacco bright Yellow-2 cell through generation of apoplast oxidation. Int J Mol Sci. 2017;18(7):1346.

53. Yamamoto A, Bhuiyan MN, Waditee R, Tanaka Y, Esaka M, Oba K, Jagendorf AT, Takabe T. Supressed expression of the appoplastic ascorbate oxidase gene increases salt tolerance in tobacco and Arabidopsis plants. J Exp Bot. 2005:56(417):1785-96.

54. Liszkay A, Der Zalm EV, Schopfer P. Production of reactive oxygen intermediates $\left(\mathrm{O}_{2}^{-}, \mathrm{H}_{2} \mathrm{O}_{2}\right.$ and $\left.\mathrm{OH}\right)$ by maize roots and their role in wall loosening and elongation growth. Plant Physiol. 2004;136(2):3114-23.

55. Bi YM, Kant S, Clark J, Gidda S, Ming F, Xu JY, Rochon A, Shelp BJ, Hao LX, Zhao R, Mullen RT, Zhu T, Rothstein SJ. Increased nitrogen-use efficiency in 
transgenic rice plants over-expressing a nitrogen-responsive early nodulin gene identified from rice expression profiling. Plant Cell Environ. 2009; 32(12):1749-60.

56. Fukayama H, Tamai T, Taniguchi Y, Sullivan S, Miyao M, Nimmo HG. Characterization and functional analysis of phosphoenolpyruvate carboxylase kinase genes in rice. Plant J. 2006;47(2):258-68.

57. Van Quy L, Foyper C, Champigny ML. Effect of light and $\mathrm{NO}_{3}{ }^{-}$on wheat leaf phosphoenolpyruvate carboxylase activity: evidence for covalent modification of the $C_{3}$ enzyme. Plant Physiol. 1991;97(4):1476-82.

58. Chollet R, Vidal J, O'Leary MH. Phosphoenolpyruvate carboxylase: a ubiquitous, highly regulated enzyme in plants, annual review of plant physiology and plant. Mol Biol. 1996;47(1):273-98.

59. Nimmo HG. Control of the phosphorylation of phosphoenolpyruvate carboxylase in higher plants. Arch Bioche Biophysisc. 2003;414(2):189-96.

60. Chen L, Hao L, Condon AG, Hu YG. Exogenous GA3 application can compensate the morphogenetic effects of the GA-responsive dwarfing gene Rht12 in bread wheat. PLoS One. 2014;9(1):e86431.

61. Schultink A, Naylor D, Dama M, Pauly M. The role of the plant-specific ALTE RED XYLOGLUCAN19 protein in Arabidopsis cell wall polysaccharide Oacetylation. Plant Physiol. 2015;167(4):1271-83.

62. Sénéchal F, Graff L, Surcout O, Marcelo P, Rayon C, Bouton S, Mareck A, Mouille G, Stintzi A, Höfte H, Lerouge P, Schaller A, Pelloux J. Arabidopsis PECTIN METHYLESTERASE17 is co-expressed with and processed by SBT35, a subtilisin-like serine protease. Ann Bot. 2014;114(6):1161-75.

63. Wang HH, Guo Y, Lv F, Zhu HY, Wu SJ, Jiang YJ, Li FF, Zhou BL, Guo WZ, Zhang TZ. The essential role of GhPEL gene, encoding a pectate lyase, in cell wall loosening by depolymerization of the de-esterified pectin during fiber elongation in cotton. Plant Mol Biol. 2010;72(s4-5):397-406.

64. Zhang BC, Zhang L, Li F, Zhang DM, Liu XL, Wang H, Xu ZP, Chu CC, Zhou $\mathrm{YH}$. Control of secondary cell wall patterning involves xylan deaceylation by a GDSL esterase. Nat Plants. 2017;3:17017.

65. Schaller A, Stintzi A, Graff L. Subtilases-versatile tools for protein turnover, plant development, and interactions with the environment. Plant Plantarum. 2012;145(1):52-66.

66. Voiniciuc C, Heinrich-Wilhelm Schmidt M, Berger A, Yang B, Ebert B, Scheller HV, North HM, Usadel B, Günl M. MUCILAGE-RELATED10 produces galactoglucomannan that maintains pectin and cellulose architecture in Arabidopsis seed mucilage. Plant Physiol. 2015;169(1):403-20.

67. Busse-Wicher M, Gomes TCF, Tryfona T, Nikolovski N, Stott K, Grantham NJ, Bolam DN, Skaf MS, Dupree P. The pattern of xylan acetylation suggests xylan may interact with cellulose microfibrils as a twofold helical screw in the secondary plant cell wall of Arabidopsis thaliana. Plant J. 2014;79(3):492-506.

68. Jensen JK, Kim H, Cocuron JC, Orler R, Ralph J, Wilkerson CG. The DUF579 domain containing proteins IRX15 and IRX15-L affect xylan synthesis in Arabidopsis. Plant J. 2011;66(3):387-400.

69. Lefebvre V, Fortabat MN, Ducamp A, North HM, Maia-Grondard A, Trouverie J, Boursiac Y, Mouille G, Durand-Tardif M. ESKIMO1 disruption in Arabidopsis alters vascular tissue and impairs water transport. PLoS One. 2011:6(2):e16645.

70. Manabe Y, Verhertbruggen Y, Gille S, Harholt J, Chong SL, Pawar PMA, Mellerowicz EJ, Tenkanen M, Cheng K, Pauly M, Scheller HV. Reduced wall acetylation proteins play vital and distinct roles in cell wall O-acetylaton in Arabidopsis thaliana. Plant Physiol. 2013;163(3):1107-17.

\section{Publisher's Note}

Springer Nature remains neutral with regard to jurisdictional claims in published maps and institutional affiliations.

Ready to submit your research? Choose BMC and benefit from:

- fast, convenient online submission

- thorough peer review by experienced researchers in your field

- rapid publication on acceptance

- support for research data, including large and complex data types

- gold Open Access which fosters wider collaboration and increased citations

- maximum visibility for your research: over $100 \mathrm{M}$ website views per year

At BMC, research is always in progress.

Learn more biomedcentral.com/submissions 